\title{
Pessoa e Dignidade Humana
}

\author{
Urbano Zilles \\ Curitiba: Editora CRV, 2012. 110 p. \\ ISBN: 978-85-8942-483-6
}

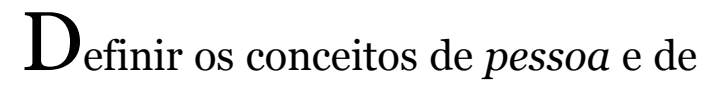
dignidade humana é um dos dilemas da ética contemporânea. Alguns princípios humanísticos substanciais, que se fundamentavam numa ordem transcendente, desvanecem com a secularização. Os sentidos que os termos pessoa e dignidade humana abarcavam foram destituídos da fonte elementar: a realidade sobrenatural. A partir de então, "o ser humano deixou de ter um valor absoluto na perspectiva atual das ciências, diluindo-se a diferença entre ele e os outros animais" (p. 9). Desse modo, todas as características essenciais que distinguiam o ser humano dos seres tidos como inferiores passam a não ter significados valorativos. Sob essa perspectiva, o homem é um super-animal biologicamente evoluído que, na escala de valores, não pode ser colocado acima de qualquer outra espécie. Não mais faz sentido afirmar que o conceito de pessoa refere-se a seres semelhantes a Deus. Doravante, é Deus que é semelhante ao homem. Para compreender as causas desse problema, Urbano Zilles examina o processo de racionalização e de secularização dos conceitos de pessoa e de dignidade. O livro é composto por dois capítulos mais amplos, em que são perscrutados esses conceitos, e outros três menores, em que são tratados os temas derivados dos respectivos conceitos.
No primeiro, em que discorre sobre o tema $O$ homem como pessoa, Zilles aborda o conceito de pessoa em cinco contextos: (i) na antiguidade, (ii) no cristianismo, (iii) na Idade Média, (iv) na modernidade e (v) na contemporaneidade. (i) Ao tratar da antiguidade, o autor, depois de ter passado rapidamente pela definição socrático-aristotélica de homem como ser racional, esclarece a origem etimológica do termo persona. Da relação entre pessoa e cosmos, o teatro explicita o todo harmonioso no qual o homem está inserido. A pessoa trágica é apenas um ator que se transfigura por meio de diversas máscaras e age dentro de um espaço inteiramente pré-determinado. Desprovido de liberdade e submetido à necessidade da natureza, a persona se depara com a inevitável realidade da morte. Entrementes, é a partir dessa compreensão da persona teatral - que mascara sua pessoalidade no palco - que os romanos empregarão o termo pessoa como metáfora de papel social - a sociedade passa a ser contemplada como o grande palco da vida. (ii) No cristianismo, o termo persona sai do âmbito social-cosmológico para ser aplicado na teologia. Os padres da Igreja, para conseguirem dar cabo de um dos grandes problemas teológicos - de esclarecer racionalmente a Trindade -, lançam mão do conceito de persona. Deus é Uno e Trino porque as pessoas - 
Pai, Filho e Espírito Santo - diferenciamse somente pela relação. A substância do Pai está presente nas três pessoas uniformemente, sendo Cristo possuidor de duas naturezas: a divina e a humana. A partir desta colocação, o cristianismo introduz "o significado ontológico na compreensão de pessoa" (p. 25) e, ato contínuo, universaliza-o para todos os sujeitos - dando um passo muito além dos romanos, que consideravam pessoa apenas os cidadãos livres. (iii) $\mathrm{Na}$ Idade Média, Boécio atribui ao conceito de pessoa a autonomia. O ser humano é uma "substância individual de natureza racional” (p. 25). A pessoa é dotada de controle de si. Não é um joguete do destino (concepção dos estoicos e, de certa forma, dos tragediógrafos). Ela não se submente às forças exteriores, pois consegue conduzir-se a si mesma, ter domínio sobre suas ações. (iv) $\mathrm{Na}$ modernidade, essa relação é invertida. A autonomia não alude somente ao controle da ação, pois o ser humano é um ser capaz de criar as próprias leis. O imperativo categórico kantiano apresenta o conceito de pessoa como ser racional que estabelece leis morais válidas universalmente. Não há compromissos religiosos e cosmológicos. Pessoa é todo ser detentor de liberdade e razão. Qualquer privação dessas duas qualidades torna a pessoa um objeto, pois desconsiderar sua liberdade ou razão é concebê-la como meio, não como um fim em si. (v) $\mathrm{Na}$ contemporaneidade, Zilles investiga os filósofos da fenomenologia - e os que sofreram forte influência da escola fenomenológica -, que tentam destituir a pessoa de sua consciência fechada e afirmá-la como consciência que tende sempre ao Outro. Desse modo, a relação intersubjetiva é o princípio de compreensão da pessoa, a qual é "[...] capaz de relacionar-se com outro e em si e por si” (p. 36). O outro é uma abertura da pessoa para a realidade extramundana. Esta será uma das teses centrais concebidas pelos personalistas, que "definem a pessoa como relacionada essencialmente com outra pessoa" (p. 41). A pessoa se constitui por meio de uma autonomia em relação ao ser, autoconsciência, comunicação e autotranscedência que "depende dos outros homens, da comunidade histórica e do mundo exterior [...]" (p. 49). Não há renúncia de sua identidade pessoal. Muito pelo contrário. Tudo isso compõe sua singular dignidade.

$A$ dignidade humana intitula $\mathrm{o}$ segundo capítulo, que se inicia com a seguinte pergunta: "o que se entende por dignidade humana?” (p. 51). Zilles reponde à questão tomando como referência o problema da dignidade concorde o valor interior do homem. Antes de compreender o que é a dignidade humana, cabe definir o que é humanum. $\mathrm{O}$ autor elenca algumas definições e conclui que "[...] a humanidade é, por um lado, um dado real e, por outro, uma tarefa a ser realizada como possibilidade sempre nova" (p. 52). Uma tarefa sempre nova, porque a busca pela definição de o que significa dignidade humana é interminável e sempre se faz presente. Tomando como base as novas definições sobre a dignidade, Zilles salienta os perigos das teorias reducionistas, tomando como exemplo a ética de Peter Singer e a argumentação 
cientificista que se baseia no darwinismo para provar que os animais têm tanta dignidade quanto o homem. A definição de homem como "[...] um todo corpóreoespiritual, que não se reduz às escolhas que faz, nem às suas qualidades exteriores e contingentes" (p. 54) refuta os reducionismos comumente concebidos como verdades irrefutáveis. Sempre se esforçando para remontar o quadro histórico a fim de conseguir visualizar melhor a constituição do conceito examinado, Zilles investiga a dignidade, como o fez com o conceito de pessoa, atravessando os principais períodos da história. Sendo assim, na antiguidade, a dignidade humana relaciona-se com a capacidade de exercer o que é próprio da natureza humana, ou seja, todo ser humano tem o dever de tornar-se aquilo para o qual é vocacionado. A dignidade é fundamentada em características inerentes ao homem, sendo a lei moral a sua garantia. Já na Idade Média, a dignidade humana está vinculada à ideia de imagem e semelhança de Deus. Todo ser humano nasce com a dignidade divina. Com a passagem para o Renascimento, essa concepção heterônoma perde espaço para a concepção autônoma. A dignidade deixa de ser um atributo divino para ser um atributo da razão, da liberdade, da criatividade. $\mathrm{Na}$ Modernidade, a valorização do homem em relação aos outros seres se torna absoluta, visto que a pessoa tem valor absoluto. Immanuel Kant é o principal arauto do homem ou, em outros termos, da perspectiva do ser humano como ser autônomo. Ou seja: a o ser humano como ser autônomo. Por fim, nos tempos atuais, o problema da dignidade se entrelaça com as duas noções até então discutidas: heteronomia e autonomia. São dois pontos de vista que se dividem e, ao mesmo tempo, tocam-se em certos instantes: o secular e o religioso.

No terceiro capítulo, Sujeito $d a$ dignidade, Zilles considera os problemas de definição do conceito de sujeito. De forma bem sucinta, o autor demonstra que houve uma progressão secular no modo de se compreender a dignidade do sujeito. Afastando-se cada vez mais da perspectiva sagrada, filósofos como Locke e Kant adotam o conceito de pessoa do direito e rejeitam o reducionismo ontológico. Autoconsciência e autonomia passam a ser conceitos determinantes para a compreensão de pessoa. Deste conceito advirá a diferença entre os dois filósofos. Kant não define a pessoa como ser autoconsciente. Para ele, isso não basta. $\mathrm{O}$ conceito de homem está vinculado ao de pessoa. "A pessoa é sujeito da dignidade" (p. 80). Não importa o estado da pessoa, contrariando Peter Singer, para Kant, ela sempre terá um valor absoluto. No final do capítulo, Zilles apresenta a definição de Henrique C. de Lima Vaz do homem como ser espiritual, que se relaciona "[...] consigo mesmo, com o mundo, com os semelhantes e com o transcendente" (p. 84). É na realidade espiritual que a dignidade humana tornar-se humana, portanto.

No quarto capítulo, Pessoa e vida humana, Zilles discorre sobre questões recentes que envolvem a ética aplicada como, por exemplo, a manipulação de células-tronco. A definição de pessoa e de dignidade humana envolve diretamente o problema da determinação do início da vida. Se no ato da concepção - ou até mesmo 
antes dela, como na filosofia aristotélica - já está presente a potencialidade humana, o conjunto de células tem todo o respaldo jurídico/teológico/filosófico que teria uma pessoa plenamente formada; do contrário, seria apenas um agregado de células como qualquer outro e poderia ser manipulado, desconsidera-se a dignidade humana. Todo o problema envolvendo a manipulação humana é um problema de definição de pessoa. Se não houver uma correlação entre pessoa e homem ou pessoa e indivíduo, o conceito de pessoa será restritivo e excludente. Se, por outro lado, houver uma correlação entre pessoa e homem ou pessoa e indivíduo, o conceito de pessoa será de aceitação, considerando o conceito de pessoa como não biológico.

Zilles escreve com leveza sobre temas árduos. Sabe lidar com problemas complexos sem cair num pedantismo esterilizante. A capacidade de relacionar as questões é notória, visto que sua obra é um todo orgânico, em que os conceitos se entrelaçam do início ao fim. Não há quebras definitivas de um capítulo para o outro. Tudo é bem composto. É muito perceptível esse arranjo no último capítulo do livro. Todas as teorias discutidas se entrecruzam. Em Dignidade e direitos humanos, último capítulo, Zilles se atém à Declaração Universal da ONU. Para ele, apesar de constatar a dignidade da pessoa, a Declaração não fundamenta esse conceito por considerála evidente. Estabelecer, portanto, os conceitos de dignidade e de pessoa é tarefa primordial, pois, como afirma o próprio autor, eles são o “’[...] núcleo fundante da moral" (p. 97). Destarte, o livro oferece suporte, em termos de conteúdo, e ampla referência bibliográfica para quem quiser se aprofundar no assunto. Serve tanto para pessoas leigas, que queiram sair do plano da mera opinião e se dirigir para o do conhecimento, quanto para especialistas, que tentam obter algum esclarecimento acerca de problemas penosos.

Rodrigo de Abreu Oliveira

Especialista em Ciências da Religião pela Pontifícia Universidade Católica de Minas Gerais, Belo Horizonte, Minas Gerais. Mestre em Estética e Filosofia da Arte pela Universidade Federal de Ouro Preto, Ouro Preto, Minas Gerais, Brasil. Doutorando em Filosofia Moderna pela Universidade Federal de Minas Gerais. E-mail: rodrigodeao@gmail.com 